\title{
RANCANG BANGUN APLIKASI PEMASARAN HELM BERBASIS AUGMENTED REALITY
}

\author{
Angkasa Julio Putra Perdana \\ Program Studi Teknik Informatika \\ Universitas Trilogi \\ email : rakajulio@trilogi.ac.id \\ Jalan Taman Makam Pahlawan No. 1, Kalibata, Pancoran, Kota Jakarta Selatan, Daerah \\ Khusus Ibukota Jakarta 12760, Indonesia

\begin{abstract}
Helmet sellers usually display helmets in their shops, but limited store area make helmets can display limited. Augmented Reality is a technology that combines three-dimensional virtual objects in a real environment. The implementation of Augmented Reality in marketing helmet sales can solved the problem by reducing the space used to display helmets and be changed in virtual form.
\end{abstract}

Kata kunci:Augmented Reality,Marketing, Helmet

\begin{abstract}
Abstrak
Penjual helm biasanya memajang helm pada tokonya namun luas toko yang terbatas tidak dapat memajang semua jenis helm. Augmented Reality adalah teknologi yang mengganbungkan benda maya tiga dimensi dalam sebuah lingkungan nyata. Implementasi Augmented Reality dalam pemasaran penjualan helm dapat mengatasi masalah dengan mengurangi space yang digunakan untuk memajang helm dan diubah dalam bentuk maya.
\end{abstract}

Kata kunci:Augmented Reality, Pemasaran, Helm,

\section{PENDAHULUAN}

Helm merupakan salah satu perlengkapan wajib yang harus digunakan khususnya untuk pengendara motor. Beberapa orang memanfaatkan kesempatan ini untuk membuka usaha yaitu usaha penjualan helm. Tempat penjualan helm biasanya menjualkan produknya dengan memajangnya pada sebuah lemari atau etalase. Berbagai jenis helm dengan segala merk telah muncul di pasaran sebanding dengan meningkatnya pengguna kendaraan bermotor khususnya roda dua. Penjual helm harus mengikuti pasar agar usahanya tidak mengalami kemunduran.

Semakin banyaknya helm yang muncul dipasaran membuat penjual helm mengalami masalah. Teknik pemasaran yang selama ini dilakukan dengan memajang helm tersebut pada sebuah lemari atau etalase memiliki batas sesuai dengan ukuran lemari atau elatalase tersebut. Semakin bertambah jumlah helm yang muncul di pasaran maka semakin besar kebutuhan ruang untuk memajang helm tersebut. Memenuhi kebutuhan tersebut membutuhkan biaya untuk merealisasikan perluasan ruangan. Selain itu helm-helm dengan model terbaru akan muncul seiring dengan semakin besarnya pasar penjualan helm. 
Augmented reality adalah teknologi yang menggabungkan objek maya berbentuk $2 \mathrm{D}$ atau 3D dengan dunia nyata secara real-time. Objek maya tersebut dapat dilihat pada dunia nyata melalui kamera. Kamera tersebut menangkap sebuah gambar dan diolah oleh aplikasi augmented reality dan akan menampilkan sebuah objek pada layar. Augmented reality menangkap gambar yang disebut marker untuk menampilkan sebuah objek pada aplikasi yang telah dibuat. Kemampuan dari teknologi augmented reality telah dimanfaatkan dari bidang pendidikan sampai bidang ekonomi.

Tekmologi augmented reality dapat mengatasi masalah terbatasnya ruang untuk memajang helm. Memindahkan helm dalam bentuk maya dapat mengurangi helm yang dipajang. Aplikasi berbasis augmented reality dapat menampilkan helm yang dilihat customer secara real-time menyerupai bentuk asli dalam bentuk 3D.

\section{METODOLOGI PENELITAN}

Tahapan yang dilakukan pada penelitian ini digambarkan pada gambar 2.1

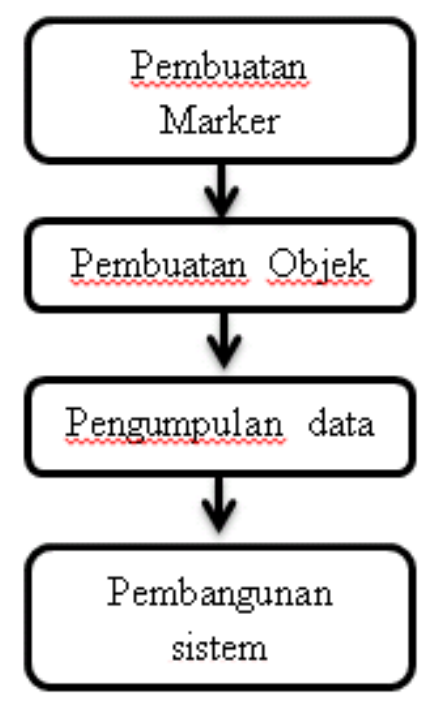

Gambar 2.1 Tahapan penelitian

\subsection{Pembuatan Marker}

Marker adalah suatu objek yang berbentuk nyata yang digunakan pada augmented reality. Fungsi dari marker adalah sebagai objek yang akan ditangkap sistem. Hasil dari penangkap citra marker tersebut adalah objek yang telah dibuat dan diprogram.

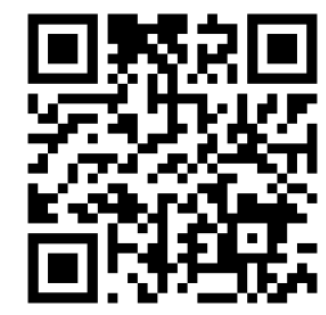

Gambar 2.1.1 Contoh Marker 


\subsection{Pembuatan Objek}

Tahap ini adalah proses pembuatan objek maya yang digunakan. Objek pada penelitian ini 3D. Objek yang telah dibuat akan terintegrasi dengan marker agar dapat ditampilkan pada computer atau handphone.

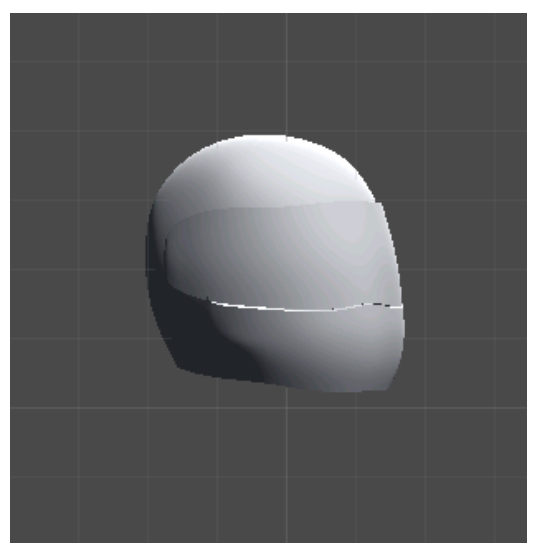

Gambar 2.2.1 Objek 3D Helm

\subsection{Pengumpulan Data}

Tahap ini adalah proses pengumpulan data berhubungan dengan helm yang akan dimasukan dalam penelitian. Data yang dikumpulkan berupa gambar helm 2D, merek helm beserta tipenya, penjelasakan singkat yang berisi keunggulan helm tersebut, serta harga jual. Hasil pengumpulan data akan dimasukan bersama dengan marker dan dicetak.

\section{GREAT GRAY}
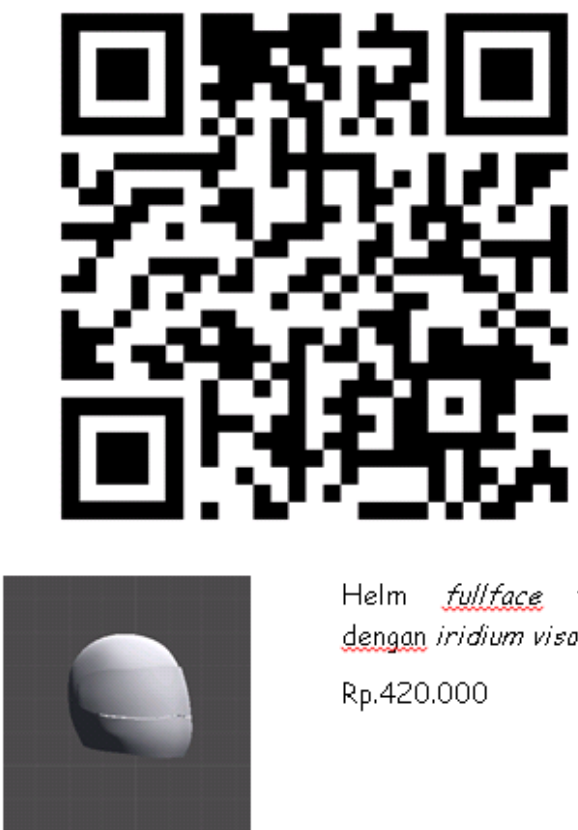

Helm fullface trendy dengan iridium visor

Rp.420.000

Gambar 2.3.1 Printed Data 


\subsection{Pembangunan Sistem}

Tahap ini adalah proses integrasi antara marker dengan objek pada aplikasi.

\subsubsection{Use Case Diagram}

Use case diagram adalah pemodelan yang dapat digunakan sebagai penggambaran behavior sistem. Use case diagram menggambarkan user dalam keterlibatan sistem.

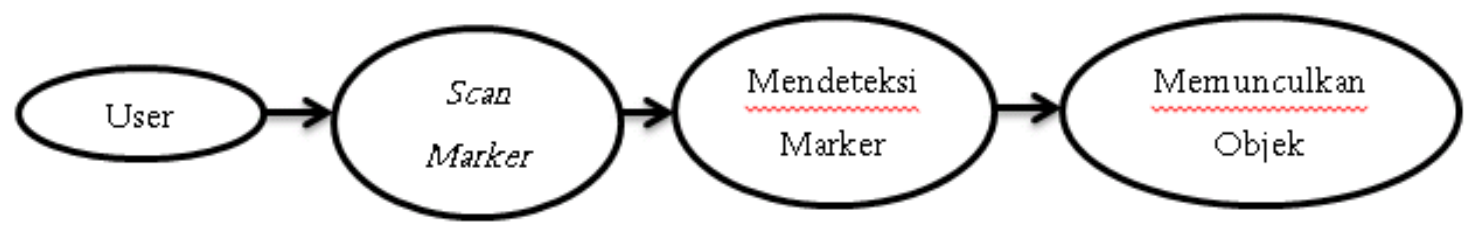

Gambar 2.4.1.1 Use Case Diagram

\subsubsection{Diagram Activity}

Diagram activity adalah sebuah penggambaran dari alur kerja yang berisi tindakan dan aktivitas yang terjadi pada sistem. Diagram activity berisi alur dan kegiatan yang dilakukan oleh beberapa user dan sistem.

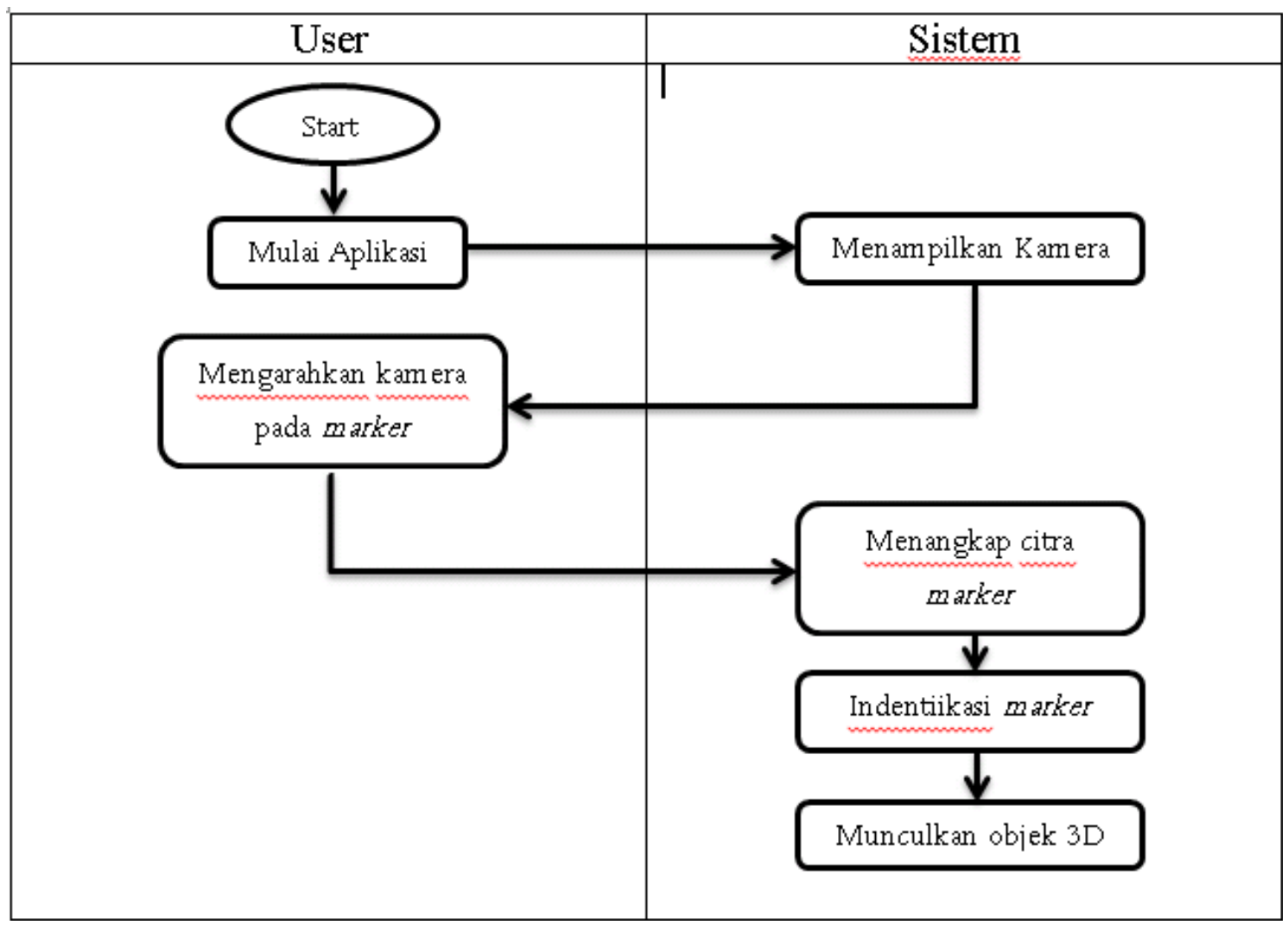

Gambar 2.4.2.1 Diagram Activity 


\section{HASIL DAN PEMBAHASAN}

3.1 Hasil pengelolahan data dan marker

Data yang telah dikumpulkan digabungkan dengan marker lalu dicetak dibentuk seperti album.

GREAT GRAY
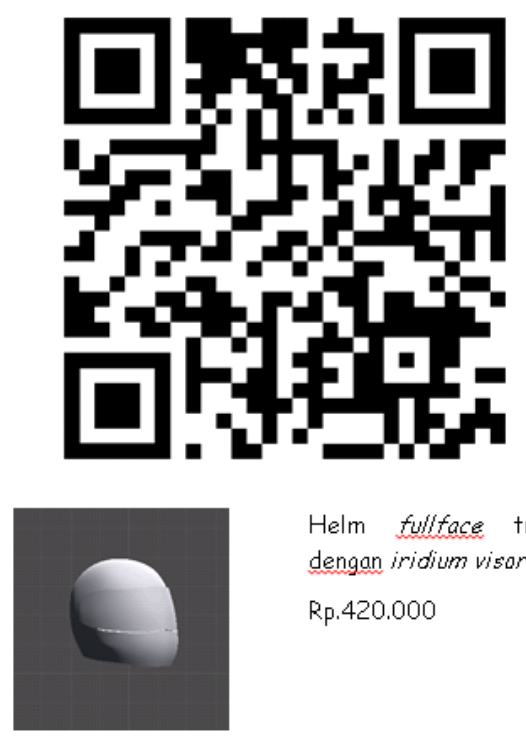

Helm fulftace trendy dengan iridium visor

Rp.420.000

Gambar 3.1.1 Marker model helm (1)

CLASSIC GRAY
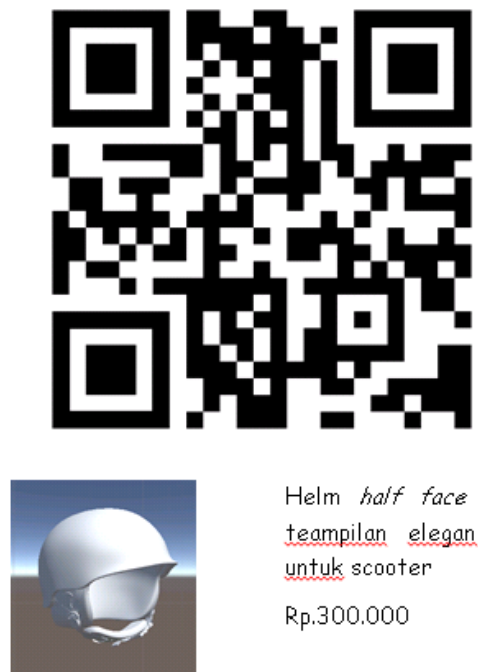

Helm half face dengan

teampilan elegan cocok

untuk scooter

Rp.300.000

Gambar 3.1.2 Marker model helm (2)

\subsection{Aplikasi}

Setelah aplikasi dimulai, user akan diarahkan untuk scan marker yang terdapat pada hasil cetak album sebelumnya. 


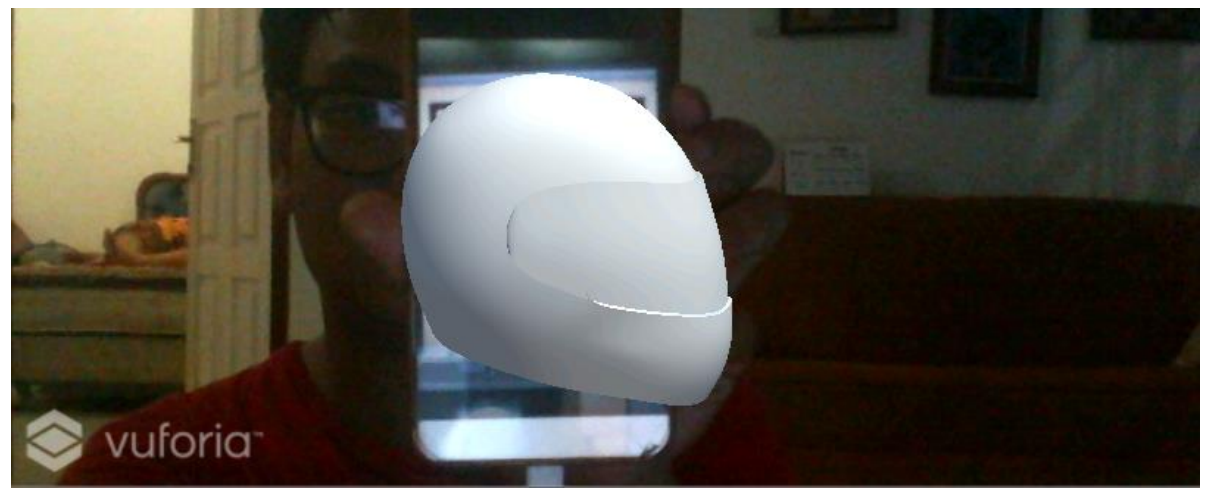

Gambar 3.2.1 Uji coba marker

\section{KESIMPULAN}

Aplikasi pemasaran helmet menggunakan augmented reality dapat mengurangi penggunaan ruangan untuk memajang helm pada tempat penjualan helm. Augmented reality adalah sebuah teknologi yang menghubungkan antara dunia virtual dengan lingkungan nyata. Kebutuhan dari aplikasi augmented reality adalah objek maya pada aplikasi dan marker yang dicetak pada lingkungan nyata. Marker dicetak bersama dengan informasi tentang helm yang dimasukan pada aplikasi. Harapan dari aplikasi ini adalah dapat mengurangi penggunaan ruang untuk memajang helm yang akan terus bertambah dipasaran.

\section{Referensi}

Santoso, A., \& Noviandi, E. (2013). Rancang Bangun Aplikasi Pembelajaran Organ Tubuh Berbasis Augmented Reality. Jurusan Teknik Informatika, STMIK GI MDP, $1-9$.

Aditya Nugraha, I. G., Putra, I. K. G. D., \& Sukarsa, I. M. (2016). Rancang Bangun Aplikasi Augmented Reality Museum Bali Berbasis Android Studi Kasus Gedung Karangasem dan Gedung Tabanan. Lontar Komputer : Jurnal Ilmiah Teknologi Informasi, 7(2), 93. https://doi.org/10.24843/lkjiti.2016.v07.i02.p03

Rahayu, S. L., Kusrini, \& Fatta, H. Al. (2016). Rancang Bangun Augmented Reality Pada Data Menu Restoran. Eksplora Informatika, 6(1), 22-32. Retrieved from https://eksplora.stikom-bali.ac.id/index.php/eksplora/article/view/101/84 